\title{
Factors that Influence the Frequency of Having Breakfast
}

\author{
Siqi Zhang \\ College of Arts and Science, Boston University, 02215, Boston, MA, United States \\ siqizh1996@icloud.com
}

Keywords: frequency of having breakfast, multiple linear regression.

\begin{abstract}
Although the topic of many kinds of research is related to the importance of adolescents having breakfast, almost no research talks about the elements that effect of frequency of teenager having breakfast. This study investigated the relationship between some factors and the number of breakfast a student have per week. In this study, I only chose six correlated factors as the independent variable and the frequency of people having breakfast per week as the dependent variable. I spread the questionnaire online through the Facebook page of Boston Univerity. Among all the 104 responses that I received, only 84 responses are fully completed. By using the model of multiple linear regression, we can easily get the result: only one factor - the time of the earliest morning class, is significantly related to our dependent variable. Also, the result showed that the adjusted R-Squared value is only 0.301, which means the relationship between the independent variables and the dependent variable is moderate but significantly positive, which means the result is pretty credible. Consequently, there is a strong relationship: the earlier the morning class is, the less number of breakfast a student could have. Still, the model also exists some problems such as multicollinearity and endogeneity.
\end{abstract}

\section{Introduction}

Nowadays, people start to care more and more about their health status. Since adolescence is a crucial period of a person's whole life, people always put a high value on the health status of adolescents. Recently, Yuanyang Zhang and Yuquan Huang showed many factors that can influence teenagers' health, such as environment, nutrient, mental stress.etc [1]. Among all the factors, I was shocked by one of the factor: nutriment. With the development of the economy, food is no longer a problem for most of the people, how could nutriment be one of the important factors on adolescents' health? As we all know, having meals is one of the most important ways for people absorbing nutrition. Even though most people might not be able to pair balanced nutritional diet, the least people need to do to show the carefulness to their health is having three meals a day [2]. Among these three meals, many studies had shown the importance of breakfast: one of them even pointed out that breakfast might influence the intelligence of teenagers [3-6].

As we all know, many factors can affect people's health status, such as sleeping time, smoking and mental health. There exist many studies about the factors that affect all those elements that I mentioned above [7-9]. However, there are almost no research talks about the factors that influence the frequency of people having breakfast. Therefore, this study investigated the relationship between several factors and the frequency of people having breakfast among college students in the United States.

\section{Method}

\subsection{Study Design}

In this study, I chose to make the frequency of people having breakfast as the dependent variable by using numbers of breakfasts having per week to denote. There may be many factors that could 
influence the frequency of people having breakfast. In this case, I only chose six correlated background variables that might have some relationship with our dependent variable. Therefore, by using the method of multiple linear regression, the model should be as followed:

$$
\mathrm{Y}=\beta_{0}+\beta_{1} \times X_{1}+\beta_{2} \times X_{2}+\beta_{3} \times X_{3}+\beta_{4} \times X_{4}+\beta_{5} \times X_{5}+\beta_{6} \times X_{6}+\varepsilon_{i}
$$

In this model, $\mathrm{Y}$ is the dependent variable, which represents the number of breakfast people having in one week, and others are the independent variables, which represent the background variables that I need to investigate.

The symbols of the independent variables are shown in Table 1:

Table 1: The Meaning of the Independent Variables

Symbol Variables Details

\begin{tabular}{|c|c|c|}
\hline$X_{1}$ & Undergraduate Degree & 0: Freshman 1: Sophomore 2: Junior 3: Senior \\
\hline$X_{2}$ & Gender & 0: Male 1: Female \\
\hline$X_{3}$ & Continent of Origin & 0: America 1: Asia 2: Europe 3: Australia 4: Others \\
\hline$X_{4}$ & $\begin{array}{l}\text { Grocery Expenditure per } \\
\text { Week }\end{array}$ & $\begin{array}{c}0:<\$ 10 \text { 1: } \$ 11-\$ 40 \text { 2:\$41-\$60 3: }>\$ 604: \text { Full on Dining } \\
\text { Plan }\end{array}$ \\
\hline$X_{5}$ & $\begin{array}{l}\text { Parents' Highest Degree of } \\
\text { Education }\end{array}$ & $\begin{array}{l}\text { 0: Below High School 1: High School Diploma 2: Associate } \\
\text { 3: Bachelor 4: Master 5: PhD and above }\end{array}$ \\
\hline$X_{6}$ & 1 & 0: before 9am 1:9am-11am 2: after 11am \\
\hline
\end{tabular}

\subsection{Data Collection}

The survey was made into questionnaires by Survey Monkey, a survey website, with seven questions and was handed out online through Boston University Facebook pages. Therefore, the data were all from college students in Boston University, United States. The total number of responses that we collected was 104. However, 21 individuals did not fully complete the questionnaire. Therefore, there are only 83 responses left to build the regression, which is large enough for us to use in statistical analysis.

Among all the data that we collected, the result of the dependent variable is: $14.29 \%$ of the students only have breakfast once a week; $8.16 \%$ of the students have breakfast twice a week; $13.27 \%$ of the students have breakfast three times a week; $10.2 \%$ of the students have breakfast four times a week; $8.16 \%$ of the students have breakfast five times a week; $16.33 \%$ of the students have breakfast six times a week and $29.59 \%$ of the students have breakfast every day.

For other independent variables, 31 students are freshman, 20 are Sophomore, 20 are Junior and 14 are Senior students. There were 26 males and 58 females in the questionnaires. Among all of them, most of the students are from America: $47.13 \% .14 .94 \%$ of the students are from Europe, $34.48 \%$ of them are from Asia, and 3.45\% of them are from Australia.

For the amount of grocery expenditure per week, $2.41 \%$ of the students could only spend less than $\$ 10$ per week; $34.94 \%$ of the students could spend $\$ 11$ to $\$ 40$ per week; $24.10 \%$ of the students could spend $\$ 41$ to $\$ 60$ per week; $22.89 \%$ of the students could spend more than $\$ 60$ one week, and the rest of the students, $15.66 \%$ of them spend no money on grocery and entirely depend on the dining plan provided by the University.

For the highest degree of parents' education, $3.75 \%$ of them is below high school degree; $17.50 \%$ of them are high school diploma; $1.25 \%$ of them are associates; $45.00 \%$ of them are in bachelor degree; $25.00 \%$ of them are master, and $7.50 \%$ of them are Ph.D. and above. 
For the final question: the earliest class, $32.00 \%$ of the students' class are before 9 am; $48 \%$ of the students' class is between 9 am and $11 \mathrm{am}$, and $20 \%$ of the students' class is before $11 \mathrm{am}$.

\section{Result}

By using the method of Multiple Linear Regression, the results are shown in Table 2.

Table 2: The outcome of multiple linear regression

\begin{tabular}{ccccc}
\hline Variable & Coefficient & Std. Error & t-Statistic & Sig. \\
\hline Constant & 2.499 & 0.786 & 3.178 & 0.002 \\
$X_{1}$ & 0.020 & 0.185 & 0.107 & 0.915 \\
$X_{2}$ & 0.381 & 0.488 & 0.779 & 0.438 \\
$X_{3}$ & -0.343 & 0.252 & -1.364 & 0.177 \\
$X_{4}$ & 0.129 & 0.195 & .661 & 0.511 \\
$X_{5}$ & -0.111 & 0.162 & -0.689 & 0.493 \\
$X_{6}$ & 1.667 & 0.287 & 5.815 & $<0.001$
\end{tabular}

\begin{tabular}{cc}
\hline Adjusted R-Square & 0.301 \\
\hline F-Statistics & 6.537 \\
\hline Sig. (F-Statistics) & $<0.001$
\end{tabular}

Therefore, the estimated regression equation is:

$\mathrm{Y}=2.449+0.020 \times X_{1}+0.381 \times X_{2}-0.343 \times X_{3}+0.129 \times X_{4}-0.111 \times X_{5}+1.667 \times X_{6}+\varepsilon_{i} \quad$ (2)

Since the significance level of F-Statistics is smaller than 0.001 , which means the variables have a significant impact on the dependent variable, which is the number of breakfast per week. Also, the Adjusted R-Squared value is 0.356 , which means the relationship between our independent variables and the dependent variable is moderate but significantly positive.

On the other hand, the significance level of $X_{6}$ is smaller than 0.001 , so we could know that there exists a strong correlation between the number of breakfast per week and the time of a student's earliest morning class.

\section{Conclusion}

While I was surprised that among all the background factors that I chose, only the time of the earliest class has a strong relationship with the number of breakfast eaten per week, this result also makes empirical sense: student merely have the amount of time to have a simple breakfast, such as a bowl of cereal, if he or she has a very early morning class. On the other hand, neither cultural identity, nor financial status, nor gender, nor the level of parents' degree, nor the undergraduate level of a student is able to determine the consumption of breakfast.

While looking through the whole process, I found that there still exist some problems. The data source is potentially biased. At first, I chose the post the questionnaire on the non-club Boston University Facebook pages because the population of that page includes all grades and all majors to make the data less skewed. However, the students who would like to use Boston University Facebook pages have a higher probability of being in a certain major such as business or communication - majors that need to keep in touch with the social media. Also, students from other continents might not use Facebook as much as American students. On the other hand, this model also exists some problems. For example, while choosing this model, I did not consider the issue of multicollinearity: there might exist some relation between some of the variables that I chose. Also, I did not take the problem of endogeneity into account. To better solve this kind of problem, in the further process, I need to spend more effort on the relationship between my independent variables and dependent variable. 
Even though the result might not be extremely robust, this study could hint at a larger problem of why students do not receive nutritionally intake every morning - they simply do not have enough time between the time of waking up and the time of the earliest class. To better solve this problem, I propose to not only Boston University community, but the whole academic community, to extend the time of students' morning by pushing back the start time of morning classes for growing adolescents to be nourished enough to excel in life, academically, socially and spiritually.

\section{References}

[1] Yuanyang Zhang, Yuquan Huang. The Research about Several Factors that Influence the Health Status of Chinese Teenagers [J]. Journal of Beijing Sports University, 2006, 29(1): 39-41.

[2] Yunlang Zheng. The Nutrition and Health Status of Teenagers [J]. Chinese Journal of Health Education, 2003, 19(8): 607-608.

[3] Zeng Wamh. Breakfast is the Most Important among All the Three Meals [J]. Guide of Chinese Medicine, 2004(7): 52-52.

[4] Huiliang Weng, Hongbin Wang. The Importance of Breakfast among Three Meals [J]. Parents, 1997(4).

[5] Zhizhen Wang. Breakfast is the First among All the Three Meals [J]. The Magazine of Medicine and Health Care, 2003(10A): 50-50.

[6] Shizhang Yan. Three Meals a Day and the Intelligence of Teenagers [J]. Family Medicine, 1994(5): 14-14.

[7] Stevenson I h, Bull M J T. A Study of the Factors Affecting the Sleeping Time Following Intracerebroventricular Administration of Pentobarbitone Sodium: Effect of Prior Administration of Centrally Active Drugs [J]. British Journal of Pharmacology, 1974, 50(4): 499.

\section{Stevenson I H, Bull M J T. A STUDY OF THE FACTORS AFFECTING THE SLEEPING TIME}

[8] Senaratne B C, Perera H, Fonseka P. Mental health status and risk factors for mental health problems in left-behind children of women migrant workers in Sri Lanka. [J]. Ceylon Medical Journal, 2011, 56(4): 153.

[9] Zhang W S, Xiao-Jun Z I, Shu-Xin L I. Research on Definition and Influential Factors for Smoke Temperature of the Furnace Outlet of the Horizontal Internal-combustion Oil-fired (Gas) Boiler [J]. Industrial Boiler, 2001. 